\title{
A Custom Radiopaque Thermoresponsive Chemotherapy-Loaded Hydrogel for Intratumoural Injection: An In Vitro and Ex Vivo Assessment of Imaging Characteristics and Material Properties
}

\author{
Seóna M. Rossi \\ Royal College of Surgeons in Ireland \\ Timothy E. Murray \\ Beaumont Hospital \\ John Cassidy \\ Technological University Dublin, john.cassidy@tudublin.ie
}

See next page for additional authors

Follow this and additional works at: https://arrow.tudublin.ie/scschcpsart

Part of the Oncology Commons, Radiation Medicine Commons, and the Radiology Commons

\section{Recommended Citation}

Rossi, S.M., Murray, T.E., Cassidy, J. et al. A Custom Radiopaque Thermoresponsive ChemotherapyLoaded Hydrogel for Intratumoural Injection: An In Vitro and Ex Vivo Assessment of Imaging Characteristics and Material Properties. Cardiovasc Intervent Radiol 42, 289-297 (2019). DOI: 10.1007/ s00270-018-2103-0

This Article is brought to you for free and open access by the School of Chemical and Pharmaceutical Sciences at ARROW@TU Dublin. It has been accepted for inclusion in Articles by an authorized administrator of ARROW@TU Dublin. For more information, please contact arrow.admin@tudublin.ie, aisling.coyne@tudublin.ie, gerard.connolly@tudublin.ie.

Funder: Enterprise Ireland; Royal College of Surgeons in Ireland

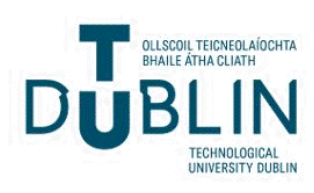


Authors

Seóna M. Rossi, Timothy E. Murray, John Cassidy, Michael J. Lee, and Helena M. Kelly

This article is available at ARROW@TU Dublin: https://arrow.tudublin.ie/scschcpsart/117 


\title{
A Custom Radiopaque Thermoresponsive Chemotherapy-Loaded Hydrogel for Intratumoural Injection: An In Vitro and Ex Vivo Assessment of Imaging Characteristics and Material Properties
}

\author{
Seóna M. Rossi ${ }^{1,2} \cdot$ Timothy E. Murray $^{3} \cdot$ John Cassidy $^{4} \cdot$ Michael J. Lee $^{3}$. \\ Helena M. Kelly ${ }^{1,2}$ (D)
}

Received: 31 July 2018/Accepted: 24 October 2018/Published online: 2 November 2018

(C) Springer Science+Business Media, LLC, part of Springer Nature and the Cardiovascular and Interventional Radiological Society of Europe (CIRSE) 2018

\begin{abstract}
Purpose Thermoresponsive hydrogels are gels which have different properties at varying temperatures. The objective of this study was to assess the material characteristics, imaging properties and chemotherapeutic drug release profile of a novel radiopaque thermoresponsive hydrogel in vitro, which is liquid at room temperature but solidifies at body temperature, to determine potential suitability for intratumoural delivery.

Materials and Methods An iodinated radiopaque thermoresponsive hydrogel was formulated using iodixanol at a range of concentrations and assessed for sol-gel transition, radiopacity and imaging using $\mathrm{CT}$ and US. A lead formulation containing iodixanol at a concentration of $9.22 \%$ weight by weight (w/w, $g$ of iodixanol per $g$ of hydrogel) was evaluated in vitro for injectability, disintegration and dual drug release of cisplatin and paclitaxel from the hydrogel formulation.

Results Radiopacity of the hydrogel increased in a concentration-dependent manner, but the highest concentration of iodixanol evaluated in this study $(13.83 \% \mathrm{w} / \mathrm{w})$
\end{abstract}

Helena M. Kelly

Helenakelly@rcsi.com

1 School of Pharmacy, Royal College of Surgeons in Ireland (RCSI), 123 St. Stephen's Green, Dublin 2, Ireland

2 Tissue Engineering Research Group, Department of Anatomy, Royal College of Surgeons in Ireland, $123 \mathrm{St}$ Stephen's Green, Dublin 2, Ireland

3 Department of Radiology, Beaumont Hospital, Dublin 9, Ireland

4 School of Chemical and Pharmaceutical Sciences, Dublin Institute of Technology, Dublin 2, Ireland adversely affected the sol-gel transition of the hydrogel; therefore, $9.22 \% \mathrm{w} / \mathrm{w}$ iodixanol hydrogel was identified as the lead formulation. This formulation was readily visible on both CT and US. The formulation was hand injectable through a range of clinically relevant devices, had a sustained disintegration profile for up to 28 days and was able to deliver a sustained release of chemotherapeutic drug for up to 10 days.

Conclusions Favourable in vitro and ex vivo imaging and material characteristics of this thermoresponsive gel are demonstrated, suggesting potential interventional oncology applications for image-guided intratumoural delivery of sustained-release chemotherapy.

Keywords Thermoresponsive hydrogel · Intratumoural injection · Radiopaque $\cdot$ Chemotherapy

\section{Introduction}

Systemic chemotherapy, in conjunction with radiation and surgery, has long been the mainstay of cancer treatment. Lack of chemotherapy specificity, toxicity, off-target side effects and poor penetration into the tumour mass due to the altered tumour microenvironment limits efficacy, which has encouraged alternative delivery methods to be investigated [1-4]. One such approach is direct injection of chemotherapeutics into the tumour, delivering chemotherapeutics or other ablative agents directly to achieve high local concentrations while reducing systemic toxicity. In vivo animal studies have shown that direct intratumoural 
instillation of a chemotherapeutic solution can deliver more than 10-30 times intravenous doses, with minimal side effects [5]. Intratumoural chemotherapy has also been explored clinically, with promising safety and proof of concept data generated [6-8]. Direct intratumoural instillation is, however, limited by rapid solution clearance from the tumour site, resulting in inaccurate and unpredictable dosing. Therefore, attention has turned to the development of drug delivery systems which can facilitate delivery and retention at the site of action, and sustained intratumoural release of chemotherapeutics [4].

Thermoresponsive hydrogels offer the possibility of an injectable liquid at room temperature that can phase transition to a semi-solid hydrogel at physiological temperatures and have been investigated in pre-clinical and clinical settings for intratumoural drug delivery in solid tumours $[9,10]$. This is an attractive drug delivery platform, due to the potential for image-guided administration without the need for surgical implantation of hardware. In situ gelation permits hydrogels to mould to the target tissue, facilitating a better fit than preformed implants [11], and facilitates sustained release of the drug at the required site of action [12-14]. Hydrogels can also be disintegrable, and the rate of disintegration can be tailored without the need for surgical removal.

Only a handful of thermoresponsive hydrogels have progressed to clinical trials, with varying degrees of success $[4,15-19]$. This lack of clinical translation may be due to the fact that whilst the studied gelling properties are of importance, other factors which are of clinical relevance such as visibility using image guidance, injectability, hydrogel distribution, drug release, retention and disintegration have not been given sufficient consideration during development. This study explores these clinically relevant factors of a novel thermoresponsive hydrogel formulation that has been specifically developed for intratumoural delivery.

\section{Methods}

\section{Formulation of a Radiopaque Thermoresponsive Hydrogel With and Without Chemotherapeutic Drug Loading}

A novel proprietary thermoresponsive hydrogel developed in a university research laboratory was prepared with a commercially available iodinated contrast agent iodixanol (Visipaque ${ }^{\circledR} 320 \mathrm{mg} \mathrm{I} / \mathrm{ml}$, GE Healthcare, IL, USA). Iodixanol was added at concentrations of $0 \% \mathrm{w} / \mathrm{w}, 4.61 \%$ $\mathrm{w} / \mathrm{w}, 9.22 \% \mathrm{w} / \mathrm{w}$ or $13.83 \% \mathrm{w} / \mathrm{w}$, based on previous work carried out by Fatimi [19]. A dual drug-loaded version of this radiopaque thermoresponsive hydrogel was prepared using two widely used chemotherapeutic agents, cisplatin and paclitaxel. Cisplatin was loaded into the aqueous phase of the thermoresponsive hydrogel with stirring. Solubilisation of paclitaxel in a formulation excipient was undertaken prior to drug loading into the thermoresponsive hydrogel.

\section{Assessment of Material Characteristics of Iodixanol- Labelled Hydrogel Formulation}

The thermoresponsivity and shear thinning properties of the hydrogel formulations were assessed using oscillatory and flow measurements, performed on a constant stress rheometer (AR-1000, TA instruments, Delaware, USA). The rheometer was equipped with cone/plate geometry (40 $\mathrm{mm}$ diameter, $4^{\circ}$ cone angle). Degassed samples were dispensed onto the temperature controlled rheometer plate, pre-equilibrated to $20{ }^{\circ} \mathrm{C}$ and covered with a solvent trap during testing. Oscillatory temperature sweeps from 20 to $40{ }^{\circ} \mathrm{C}$ were performed to determine sol-gel transition temperatures. The viscosity properties of the thermoresponsive hydrogel in response to an applied shear stress were also investigated in order to predict the material behaviour during injection. In response to an increasing shear stress applied shear thinning materials will decrease viscosity, while shear thickening materials will increase viscosity. Shear thinning materials are, therefore, the most suitable for injection purposes as the decreasing viscosity of the injectate will facilitate easier injection. Shear thinning properties of hydrogel formulations were assessed at $20{ }^{\circ} \mathrm{C}$ under increasing shear stress from 1 to $100 \mathrm{~Pa}$. All experiments were repeated in triplicate. Data were processed using TA Data Analysis software.

\section{Measurement of Radiopacity of Iodixanol-Labelled Hydrogel Formulation}

$2 \mathrm{ml}$ of iodixanol-labelled hydrogel formulation was added per well in a 12-well plate. Radiopacity was determined using a commercially available computed tomography (CT) machine (Ingenuity Core 128, Philips Healthcare, Best, The Netherlands). Spiral volumetric acquisition through each 12-well plate was obtained using $0.8 \mathrm{~mm}$ slice thickness, $0.4 \mathrm{~mm}$ reconstruction interval, $168 \mathrm{~mA} \mathrm{~s}$ and $100 \mathrm{kV}$. A region of interest $(10 \mathrm{~mm}$ diameter $)$ was positioned centrally within each well on a coronal reformat for acquisition of density measurements, ensuring only hydrogel was included within the region of interest, excluding both air and plate. The average density was calculated (minimum, maximum and standard deviation also recorded). All measurements were carried out in triplicate. Data shown are represented as the mean $\pm \mathrm{s}$ tandard error of the mean (SEM) $(n=3)$. 


\section{Assessment of Distribution of Iodixanol-Labelled Hydrogel in Ex Vivo Animal Tissue}

Ex vivo tissue (calves liver) was used to assess the distribution of injected radiopaque thermoresponsive hydrogel. Prior to injection, the ex vivo tissue was heated to $37^{\circ} \mathrm{C}$ in a water bath. Internal tissue temperature was recorded using a tissue thermometer. $5 \mathrm{ml}$ of hydrogel with $9.22 \%$ $\mathrm{w} / \mathrm{w}$ iodixanol was injected into the ex vivo tissue model using an $18 \mathrm{G} 5 \mathrm{~cm}$ vascular access needle (Cook Medical, IN, USA) at a constant rate to assess distribution of injected thermoresponsive hydrogel in tissue. Three injections were made. Administration was monitored using a commercially available $12 \mathrm{MHz}$ linear ultrasound (US) probe (Xario, Toshiba, Tokyo, Japan) in grayscale B-mode. Ex vivo distribution post-injection was imaged using CT as outlined previously.

\section{Assessment of Injectability of Hydrogel Formulation}

Uniaxial tensile testing was carried out to determine the force required to expel hydrogels from a syringe fitted with a needle or catheter, using a mechanical testing machine (Z050, Zwick/Roell, Ulm, Germany), fitted with a $5-\mathrm{kN}$ load cell (Fig. 1). Samples were loaded into $2 \mathrm{ml}$ Leur$\operatorname{lok}^{\circledR}$ syringes, and the required medical device was attached to the syringe via Luer-lok ${ }^{\circledR}$ (Table 1). A preload of $1 \mathrm{~N}$ was applied, and the end of test was determined to be the maximum extension $(8.5 \mathrm{~mm})$; the distance equivalent to $0.5 \mathrm{ml}$ of hydrogel (measured using Vernier callipers). The speed of injection was defined as $2 \mathrm{ml} / \mathrm{min}$, and the solution expelled from the catheter was collected in a vial. All measurements were carried out in a minimum of triplicate. Results are represented as the mean \pm SEM $(n=$ minimum of 3$)$.

\section{Disintegration Studies}

$1 \mathrm{~g}$ of the radiopaque thermoresponsive hydrogel formulation (blank or drug-loaded) containing $9.22 \% \mathrm{w} / \mathrm{w}$ iodixanol was added to a glass vial and submerged in a shaking water bath at $75 \mathrm{rpm}$, maintained at $37^{\circ} \mathrm{C}$, for $30 \mathrm{~min}$ to ensure complete gelation had taken place. $1 \mathrm{ml}$ of pre-warmed phosphate-buffered saline (PBS) ( $\mathrm{pH} 7.4)$ was added to the gel. At predetermined timepoints $(4 \mathrm{~h}$ and day $1,2,3,5,7,10,14,21$ and 28), PBS was completely removed from the glass vial and the weight of the hydrogel + glass vial was recorded. After weighing, $1 \mathrm{ml}$ of fresh pre-warmed PBS was added to the glass vial. All experiments were carried out in triplicate, for three independent batches. Results are represented as the mean of three independent experiments $\pm \operatorname{SEM}(n=3)$.

\section{Chemotherapeutic Release Studies}

$1 \mathrm{~g}$ of drug-loaded radiopaque thermoresponsive hydrogel containing $9.22 \% \mathrm{w} / \mathrm{w}$ iodixanol was added to a glass vial and submerged in a shaking water bath at $75 \mathrm{rpm}$, maintained at $37{ }^{\circ} \mathrm{C}$, for $30 \mathrm{~min}$ to ensure complete gelation had taken place. $1 \mathrm{ml}$ of pre-warmed PBS (pH 7.4) was added

Fig. 1 Representative image of injectability testing using a Zwick mechanical testing machine

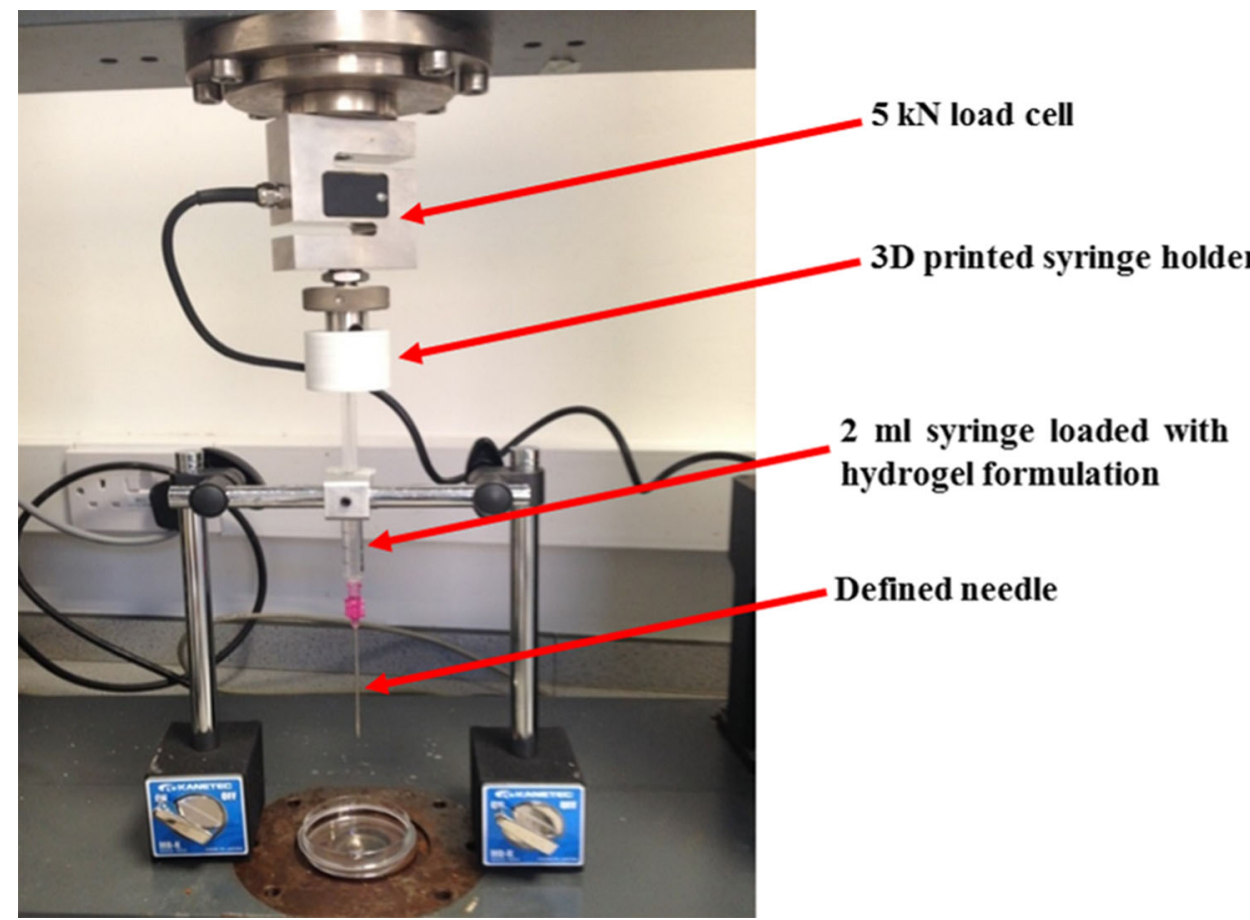


Table 1 Summary of medical devices used in injectability testing of various thermoresponsive hydrogel formulations

\begin{tabular}{lcc}
\hline Medical device & Needle gauge $(\mathrm{G}) /$ catheter diameter $(\mathrm{Fr})$ & Length $(\mathrm{cm})$ \\
\hline Cook medical needle & $18 \mathrm{G}$ & 7 \\
Cook medical needle & $18 \mathrm{G}$ & 20 \\
Chiba biopsy needle & $20 \mathrm{G}$ & 10 \\
Terumo spinal needle & $23 \mathrm{G}$ & 9 \\
Cordis catheter & $5 \mathrm{Fr}$ & 65 \\
\hline
\end{tabular}

to the gelled hydrogel, and at predetermined timepoints (4 $\mathrm{h}$ and day 1, 2, 3, 5, 7, 10, 14, 21 and 28) PBS was completely removed from the glass vial and then replaced with $1 \mathrm{ml}$ of fresh pre-warmed PBS. Samples were transferred to a centrifuge tube and stored at $-20{ }^{\circ} \mathrm{C}$ until analysis. Analysis of released paclitaxel was performed using liquid chromatography (Agilent Technologies 1120 Compact LC, CA, USA) with a UV detector, based on a method by Kraitzer et al. [20]. The mobile phase was water/acetonitrile (45:55), with a flow rate of $1 \mathrm{ml} / \mathrm{min}$, a run-time of $10 \mathrm{~min}$ and detection at $227 \mathrm{~nm}$. Analysis of released cisplatin was performed by quantifying platinum using inductively coupled plasma optical emission spectrometry (Liberty 150 ICP-MS, Varian Inc., CA, USA) at a detection wavelength of $214.423 \mathrm{~nm}$, with a plasma flow of $15 \mathrm{~L} / \mathrm{min}$, auxiliary flow $1.5 \mathrm{~L} / \mathrm{min}$ and nebulizer pressure of $200 \mathrm{kPa}$. All experiments were carried out in triplicate, for three independent batches. Results are represented as the mean of three independent experiments \pm SEM $(n=3)$.

\section{Results}

\section{Impact of Iodixanol on Sol-Gel Transition of Hydrogel Formulations}

Figure $2 \mathrm{a}$ shows the effect of increasing concentrations of iodixanol on the material characteristics of the hydrogel. The storage modulus $\left(\mathrm{G}^{\prime}\right)$ is the elastic component of the hydrogel, which is a measure of structure within the hydrogel. The sol-gel phase transition was marked by an abrupt increase in the $G^{\prime}$ of the gel, indicating a transition from liquid to semi-solid state at physiological temperatures as observed in Fig. 2b. Concentrations of iodixanol up to $9.22 \% \mathrm{w} / \mathrm{w}$ did not significantly impact on either the sol-gel transition temperature or the strength of the hydrogel. However, increasing the iodixanol concentration to $13.83 \% \mathrm{w} / \mathrm{w}$ caused a significant reduction in sol-gel transition temperature and an increase in the strength of the hydrogel.

\section{Radiopacity of Iodixanol-Labelled Hydrogel Formulations}

The addition of iodixanol solution to the hydrogel formulation was seen to produce a homogenous gelled formulation at all concentrations evaluated, as evidenced by CT imaging (Table 2). Addition of iodixanol solution resulted in increased radiopacity in a concentration-dependent manner. Gelation only minimally reduced radiopacity in all three iodixanol-labelled hydrogel groups. Due to favourable rheological and radiopacity characteristics, the hydrogel containing $9.22 \% \mathrm{w} / \mathrm{w}$ iodixanol was selected for further assessment.

\section{Distribution of Iodixanol-Labelled Hydrogel in Ex Vivo Animal Tissue}

Injection into ex vivo calves tissue (liver) demonstrated that the radiopaque thermoresponsive hydrogel $(9.22 \%$ w/w iodixanol) was readily injectable, and moulded to the shape of the target tissue. On US, it was found to be clearly visualised, anechoic and without speckling (Fig. 3a). It demonstrated excellent radiopacity on CT achieving Hounsfield units far in excesses of liver parenchyma even with the lowest strength formulations (as outlined in Table 2). The hydrogel was seen to pool in parenchyma around the needle tip at commencement of injection, and as resistance (and presumably interstitial pressures) increased, the thermoresponsive hydrogel formulation subsequently began to spread along vascular and biliary channels before undergoing gelation. Following gelation, the thermoresponsive hydrogel moulded to the shape of the tissue, without further spread indicating successful transition from liquid to semi-solid had occurred (Fig. 3c-e).

\section{Injectability of Hydrogel Formulations}

Rheological measurement of viscosity at $20^{\circ} \mathrm{C}$ demonstrated shear thinning, i.e. a decrease in viscosity with increasing shear, which is beneficial for injectability (Fig. 4a). Radiopaque hydrogel was injectable across all needle gauges evaluated, with only the $23 \mathrm{G}$ device required a force greater than $50 \mathrm{~N}$ to achieve injection (Fig. 4b). Injection through a $65-\mathrm{cm} 5-\mathrm{Fr}$ catheter was also 
Fig. 2 a Addition of iodixanol to the hydrogel formulation impacts the rheological properties of the thermoresponsive hydrogel in a concentration-dependant manner. Rheogram of the oscillatory temperature sweeps from 20 to $40{ }^{\circ} \mathrm{C}$ of hydrogel formulations containing different concentrations of iodixanol solution.

b Representative image of hydrogel formulation at room temperature, in liquid state, and following incubation at $37{ }^{\circ} \mathrm{C}$, in gelled state. Hydrogel contains colouring for clarity
A

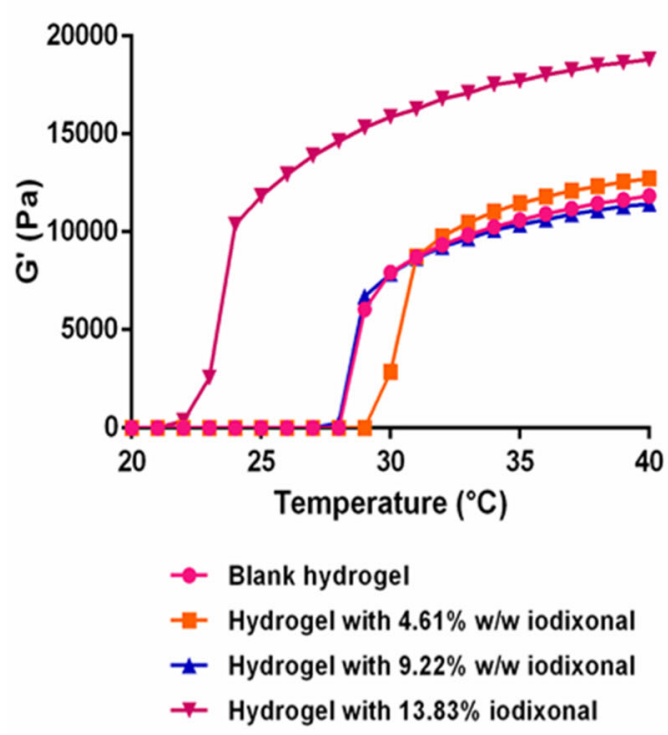

B Room temperature

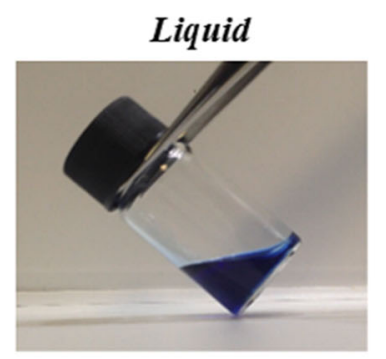

Body temperature $\left(37^{\circ} \mathrm{C}\right)$

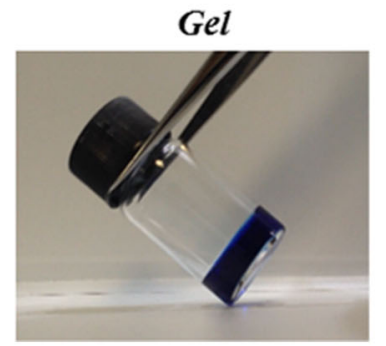

shown to be feasible. A force of $0-10 \mathrm{~N}$ was considered to correspond to an injection process which would be "easy to inject by hand", and injections which require forces up to $50 \mathrm{~N}$ to complete can be defined as "injectable by hand" [21].

\section{Disintegration and Chemotherapeutic Release from Hydrogel Formulations}

Similar disintegration profiles for both the blank and drugloaded radiopaque thermoresponsive hydrogel were observed in vitro over 28 days (Fig. 5a), with both formulations demonstrating extended disintegration profiles. An initial decrease in mass was observed for both formulations after $4 \mathrm{~h}$ of exposure with a subsequent steady decrease in mass observed thereafter until $168 \mathrm{~h}$, after which mass loss levelled off, with approx. $20 \%$ of the hydrogel still present at day 28. It is hypothesised that cross-linking occurring between components of the gel after transitioning to a gel at $37{ }^{\circ} \mathrm{C}$ contributes to the extended disintegration profile of the gel. A slow disintegration of the hydrogel is important to ensure it remains in situ for a sufficient period of time to enable the chemotherapeutic drug load to be released at the required site of action. In vitro release study of a dual drug-loaded hydrogel showed sustained release of cisplatin and paclitaxel for up to 7 days (Fig. 5b). A significant burst release of both chemotherapeutic agents was observed in the first $24 \mathrm{~h}$, with a higher burst and shorter sustained release of cisplatin. This is to be expected as cisplatin has significantly higher water solubility than paclitaxel and therefore will diffuse more rapidly into the surrounding aqueous medium driven by simple diffusion. Paclitaxel, with lower water solubility, showed a smaller burst release and a more sustained release profile for up to 7 days from the hydrogel. The rate of drug release from hydrogels has been attributed to chemical, physical and biological interactions between the hydrogel matrix, the drugs loaded and surrounding tissue, including the rate of gel disintegration [22].

\section{Discussion}

Thermoresponsive hydrogels can support the delivery of a range of chemotherapeutic agents, achieving high, and lasting, local concentrations [3, 23-25]. To transition to such clinical use however, these hydrogels must be both easily visible on imaging, and hand injectable. This study demonstrates that combining an off-the-shelf iodinated contrast preparation with a novel thermoresponsive hydrogel formulation is feasible and leads to a clearly visible formulation both radiographically (on CT) and sonographically (on US). Furthermore, testing of viscosity and injectability demonstrates these formulations are injectable with forces that can be generated by hand. Preliminary in vitro disintegration studies suggest that the hydrogel has a prolonged disintegration profile, which would indicate the potential for prolonged retention within tissue. However, the effect of biological fluid may considerably alter the disintegration profile; therefore, this will require further in vivo evaluation. Assuming that prolonged retention is achievable this offers the potential for sustained 
Table 2 Radiopacity of the thermoresponsive hydrogel formulations with increasing concentrations of iodixanol

\begin{tabular}{|c|c|c|c|}
\hline & Liquid (HU) & Gelled (HU) & $\begin{array}{l}\text { Coronal image of well plate on CT (window width } 1488 \text {, } \\
\text { level 346) }\end{array}$ \\
\hline $9.22 \% \mathrm{w} / \mathrm{w}$ iodixanol solution & $1523.7 \pm 7.09$ & N/A & \\
\hline $\begin{array}{l}\text { Thermoresponsive hydrogel with } 0 \% \mathrm{w} / \mathrm{w} \\
\text { iodixanol }\end{array}$ & $33.57 \pm 2.34$ & $22.4 \pm 2.06$ & \\
\hline $\begin{array}{l}\text { Thermoresponsive hydrogel with } 4.61 \% \text { w/w } \\
\text { iodixanol }\end{array}$ & $900.03 \pm 5.15$ & $697.11 \pm 19.28$ & \\
\hline $\begin{array}{l}\text { Thermoresponsive hydrogel with } 9.22 \% \text { w/w } \\
\text { iodixanol }\end{array}$ & $1666.23 \pm 6.98$ & $1586.0 \pm 12.03$ & \\
\hline $\begin{array}{l}\text { Thermoresponsive hydrogel with } 13.83 \% \mathrm{w} / \mathrm{w} \\
\text { iodixanol }\end{array}$ & $2428.83 \pm 19.01$ & $2378.7 \pm 13.9$ & \\
\hline
\end{tabular}

Data shown are representative of the mean $\pm \operatorname{SEM}(n=3)$

$H U$ Hounsfield units, $w / w$ weight by weight

drug release, as drug release from a 3D matrix is a function of diffusion and erosion. These results suggest that the inherent properties of this thermoresponsive hydrogel offer potential for transition to the interventional radiology suite and future treatment opportunities. This is particularly promising for infiltrative tumours which can be accessed radiologically and demonstrate response to chemotherapy, but are not amenable to ablation or resection due to adjacent vital structures. Potential applications would therefore include locally advanced pancreatic cancer, cholangiocarcinoma, glioblastoma, and infiltrating mediastinal or peritoneal tumours.

The primary limitation of this study is its experimental nature. While demonstrating that contrast-labelled chemotherapy-labelled hydrogel can be injected under image guidance in ex vivo animal liver, translation into in vivo experimentation and clinical usage still requires much investigative work. In terms of clinical translation, further study is required to establish how thermoresponsive hydrogels behave on delivery into a variety of tissue types 


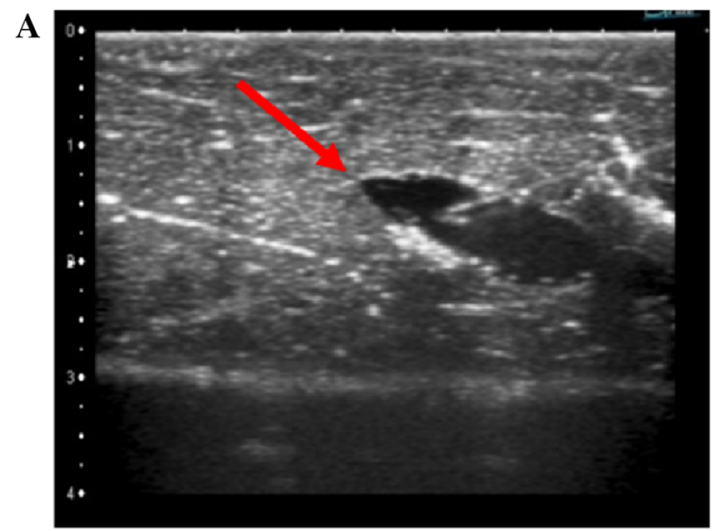

C

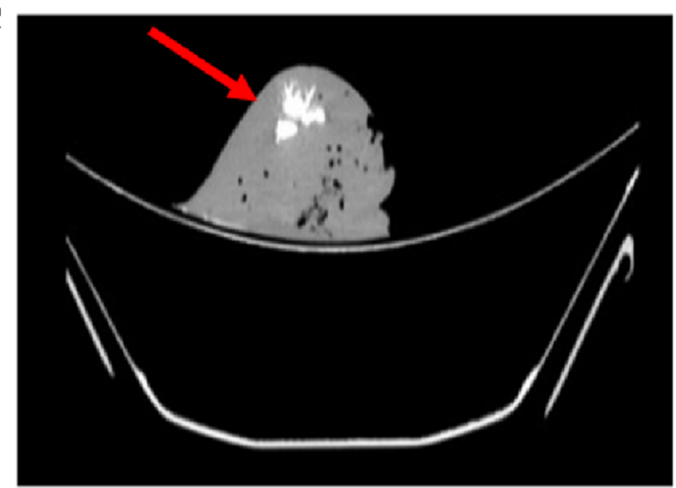

B

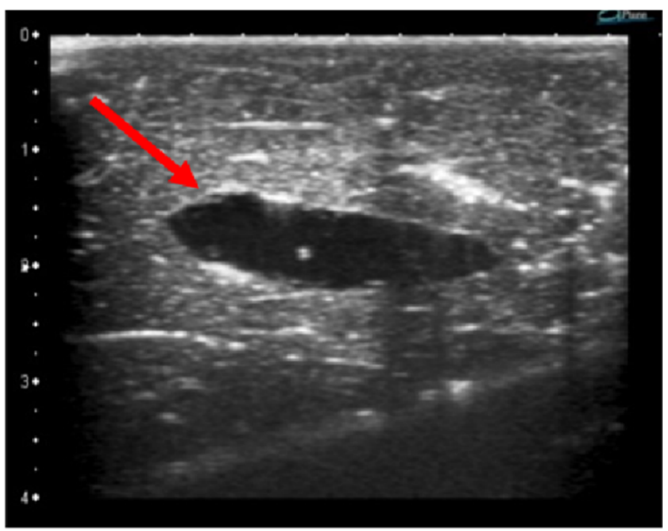

D
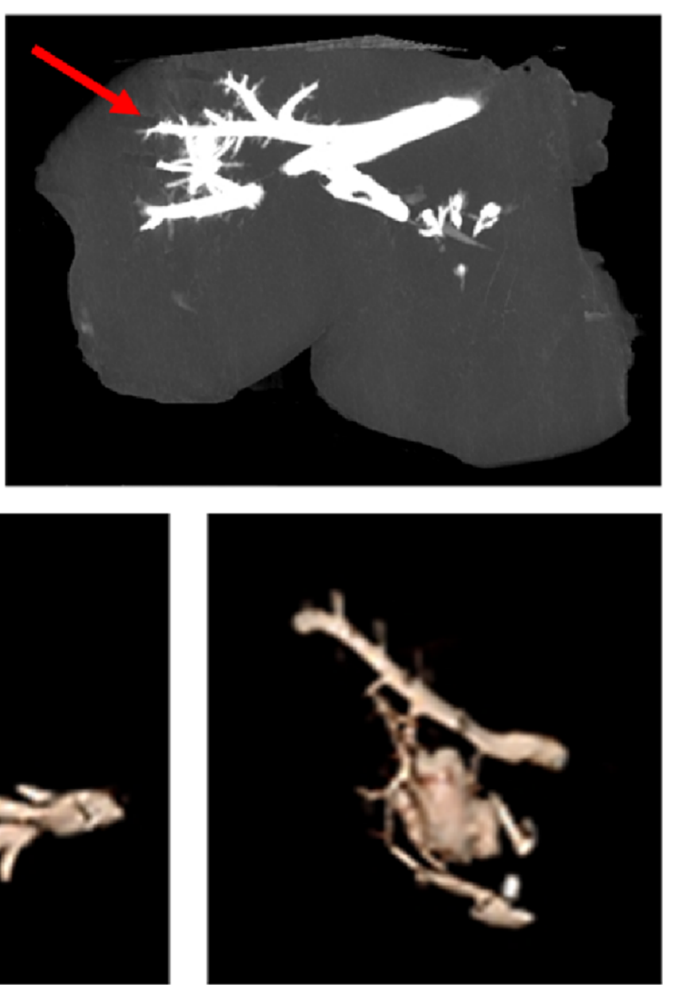

$\mathbf{E}$
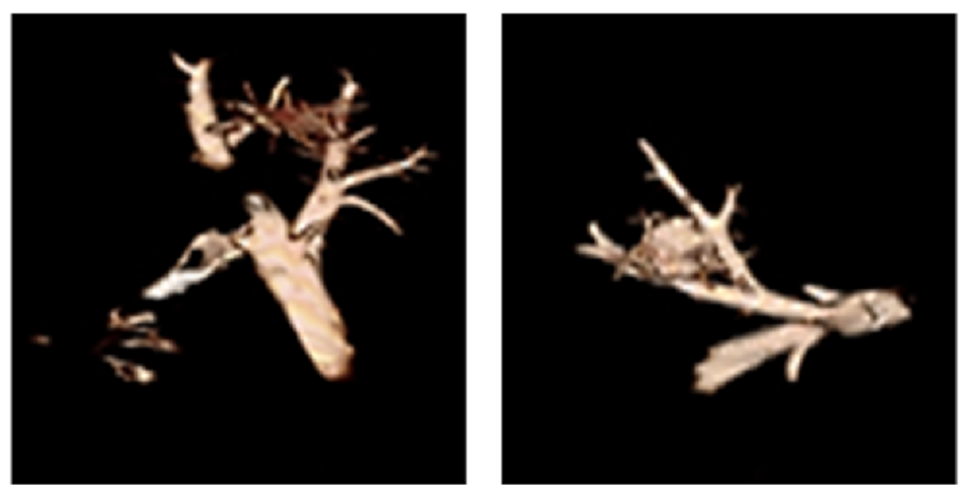

ex vivo tissue and e CT images of radiopaque hydrogel pooling at

Fig. 3 Ex vivo tissue administration of the radiopaque thermoresponsive hydrogel can be visualised using CT and US. Representative a, b US and $\mathbf{c}, \mathbf{d}$ CT images of radiopaque hydrogel distribution in

and tumour types, in particular their in vivo disintegration profile. It will also be important to establish any toxicity associated with the use of the hydrogel. Work is currently ongoing in a number of pre-clinical xenograft cancer models to establish efficacy of both the blank and chemotherapeutic-loaded thermoresponsive hydrogel, and to determine whether there is any local or systemic toxicity associated with the hydrogel. The interventional radiologist will also require an understanding of how these hydrogels behave in soft tissue. In practice, injection force and spread within various tumours and organs (and even organs in various states such as cirrhosis) can feel different. In this study, the investigators note that within calf liver, the parenchymal injection site (arrow), following which it spreads through vascular and biliary channels

hydrogel pooled at the needle tip following hand injection, and flowed into vascular and biliary channels as injection pressure and volume increased. This would need to be validated in human tissue and for each clinical indication.

\section{Conclusion}

Thermoresponsive hydrogels can be designed to transition from an injectable liquid at room temperature, to a semisolid at body temperature. This study demonstrates that this proprietary hydrogel can be loaded with various concentrations of iodinated contrast and chemotherapeutic agents 


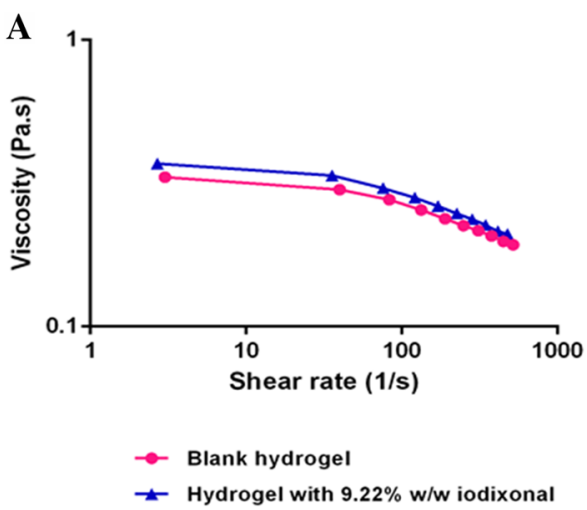

Fig. 4 a Unlabelled and contrast-labelled thermoresponsive hydrogel underwent shear thinning (a decrease in viscosity in response to increasing shear rate). Data shown is representative of the norm. b Injectability of radiopaque thermoresponsive hydrogel formulation

A

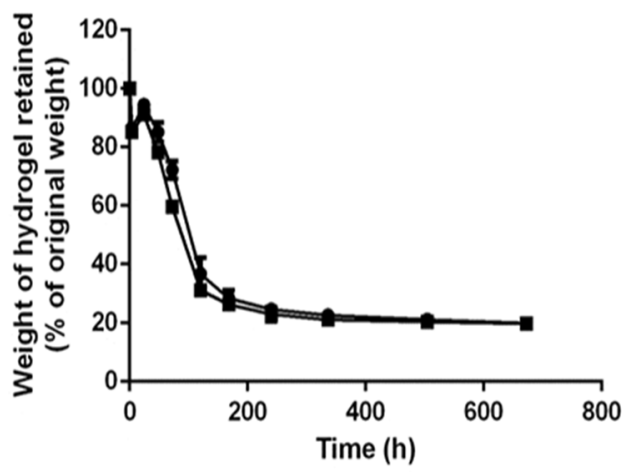

Hydrogel with $9.22 \%$ w/w iodixonal

Drug-loaded hydrogel with $9.22 \% \mathrm{w} / \mathrm{w}$ iodixonal

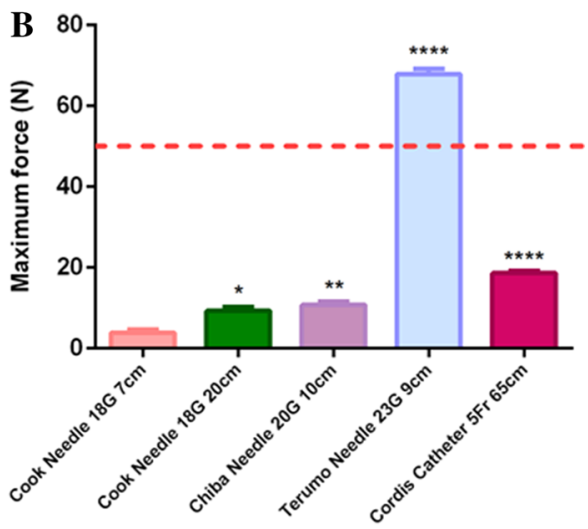

at $2 \mathrm{ml} / \mathrm{min}$. Increasing needle gauge and catheter length increases force required for injection. $* p<0.05, * * p<0.01$, *** $p<0.001$ compared to Cook needle $18 \mathrm{G} 7 \mathrm{~cm}$. Data shown are represented as the mean $\pm \operatorname{SEM}(n=3)$

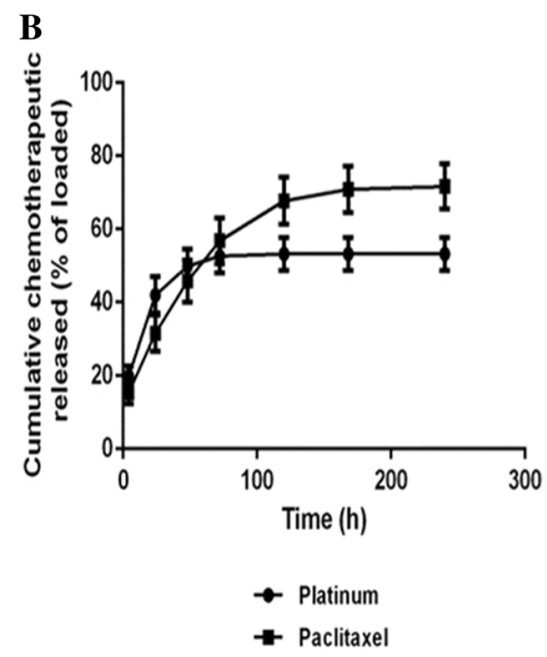

Fig. 5 a Disintegration of the blank and drug-loaded radiopaque thermoresponsive hydrogel over 28 days. Disintegration determined by measuring loss in mass ( $\%$ of original weight of hydrogel) per timepoint. b Cisplatin (measured as platinum) and paclitaxel were released in a controlled manner from the drug-loaded radiopaque

while maintaining its inherent thermoresponsive properties. Furthermore, the contrast-labelled thermoresponsive hydrogel is clearly visualised on a variety of in-use medical imaging modalities. The viscosity properties of the thermoresponsive hydrogels at room temperature permits hand injection through off-the-shelf needles and catheters. The hydrogel demonstrates a slow disintegration profile in vitro when held at body temperature, with concomitant sustained drug release. It is important to note that in vitro experiments were performed in a non-biological environment, and in vivo investigations are required to determine the disintegration profile and clinical efficacy of the thermoresponsive hydrogel. Preliminary in vitro characteristics suggest this novel thermoresponsive hydrogel may be thermoresponsive hydrogel over a 10 day period. Cumulative percentage of loaded cisplatin and paclitaxel released over a 10-day period $(240 \mathrm{~h})$. Data shown are representative of the mean of three independent experiments $\pm \operatorname{SEM}(n=3)$

suitable for application in locoregional drug delivery to solid tumours under image guidance.

Funding This study was funded by an Enterprise Ireland Commercialisation Fund (CF-2016-0431P) and a Royal College of Surgeons in Ireland School of Pharmacy bursary.

\section{Compliance with Ethical Standards}

Conflict of interest The authors declare that they have no conflict of interest.

Human and Animal Rights This article does not contain any studies with human participants or animals performed by any of the authors. 
Informed Consent For this type of study, informed consent is not required.

Consent for Publication For this type of study consent for publication is not required.

\section{References}

1. Senthebane DA, Rowe A, Thomford NE, Shipanga H, Munro D, Al Mazeedi MAM, et al. The role of tumor microenvironment in chemoresistance: to survive, keep your enemies closer. Int J Mol Sci. 2017;18(7):1586. https://doi.org/10.3390/ijms18071586.

2. Schaefer L, Reinhardt DP. Special issue: extracellular matrix: therapeutic tools and targets in cancer treatment. Adv Drug Deliv Rev. 2016;97:1-3. https://doi.org/10.1016/j.addr.2016.01.001.

3. Pearce A, Haas M, Viney R, Pearson S-A, Haywood P, Brown C, et al. Incidence and severity of self-reported chemotherapy side effects in routine care: a prospective cohort study. PLoS ONE. 2017;12(10):e0184360. https://doi.org/10.1371/journal.pone. 0184360 .

4. Wolinsky JB, Colson YL, Grinstaff MW. Local drug delivery strategies for cancer treatment: gels, nanoparticles, polymeric films, rods, and wafers. J Control Release. 2012. https://doi.org/ 10.1016/j.jconrel.2011.11.031.

5. Celikoglu F, Celikoglu SI, Goldberg EP. Techniques for intratumoral chemotherapy of lung cancer by bronchoscopic drug delivery. Cancer Ther. 2008;6:545-52.

6. Hohenforst-Schmidt W, Zarogoulidis P, Darwiche K, Vogl T, Goldberg EP, Huang H, et al. Intratumoral chemotherapy for lung cancer: re-challenge current targeted therapies. Drug Design Dev Ther. 2013;7:571-83. https://doi.org/10.2147/DDDT.S46393.

7. Levy MJ, Alberts SR, Bamlet WR, Burch PA, Farnell MB, Gleeson FC, et al. EUS-guided fine-needle injection of gemcitabine for locally advanced and metastatic pancreatic cancer. Gastrointest Endosc. 2017;86(1):161-9. https://doi.org/10.1016/j. gie.2016.11.014.

8. Hecht JR, Farrell JJ, Senzer N, Nemunaitis J, Rosemurgy A, Chung $\mathrm{T}$, et al. EUS or percutaneously guided intratumoral TNFerade biologic with 5-fluorouracil and radiotherapy for firstline treatment of locally advanced pancreatic cancer: a phase I/II study. Gastrointest Endosc. 2012;75(2):332-8. https://doi.org/10. 1016/j.gie.2011.10.007.

9. Klouda L. Thermoresponsive hydrogels in biomedical applications: a seven-year update. Eur $\mathrm{J}$ Pharm Biopharm. 2015;97:338-49. https://doi.org/10.1016/j.ejpb.2015.05.017.

10. DuVall GA, Tarabar D, Seidel RH, Elstad NL, Fowers KD. Phase 2: a dose-escalation study of OncoGel (ReGel/paclitaxel), a controlled-release formulation of paclitaxel, as adjunctive local therapy to external-beam radiation in patients with inoperable esophageal cancer. Anticancer Drugs. 2009;20(2):89-95. https:// doi.org/10.1097/CAD.0b013e3283222c12.

11. Buwalda SJ, Boere KWM, Dijkstra PJ, Feijen J, Vermonden T, Hennink WE. Hydrogels in a historical perspective: From simple networks to smart materials. J Control Release. 2014;190:254-73. https://doi.org/10.1016/j.jconrel.2014.03.052.

12. Ward MA, Georgiou TK. Thermoresponsive polymers for biomedical applications. Polymers. 2011;3(4):1215-42. https:// doi.org/10.3390/polym3031215.
13. Bajpai AK, Shukla SK, Bhanu S, Kankane S. Responsive polymers in controlled drug delivery. Prog Polym Sci. 2008;33(11):1088-118. https://doi.org/10.1016/j.progpolymsci. 2008.07.005.

14. Chen YY, Wu HC, Sun JS, Dong GC, Wang TW. Injectable and thermoresponsive self-assembled nanocomposite hydrogel for long-term anticancer drug delivery. Langmuir. 2013;29(11):3721-9. https://doi.org/10.1021/la400268p.

15. Donin NM, Duarte S, Lenis AT, Caliliw R, Torres C, Smithson A, et al. Sustained-release formulation of mitomycin $\mathrm{C}$ to the upper urinary tract using a thermosensitive polymer: a preclinical study. Urology. 2017;99:270-7. https://doi.org/10.1016/j.urology. 2016.09.039.

16. Jonsson Comprehensive Cancer Center. Compassionate use of MitoGel in upper tract urothelial carcinoma (NCT02701023). Bethesda (MD): National Library of Medicine (US). 2000-2016. https://clinicaltrials.gov/ct2/show/NCT02701023.. Accessed 02 Mar 2017.

17. DeWitt JM, Murthy SK, Ardhanari R, DuVall GA, Wallner G, Litka $P$, et al. EUS-guided paclitaxel injection as an adjunctive therapy to systemic chemotherapy and concurrent external beam radiation before surgery for localized or locoregional esophageal cancer: a multicenter prospective randomized trial. Gastrointest Endosc. 2016;1:2-3. https://doi.org/10.1016/j.gie.2016.11.017.

18. United States Food and Drug Administration. FDA ODAC Briefing Document for NDA 21-236. IntraDose ${ }^{\circledR}$ (cisplatin/epinephrine) Injectable Gel for Recurrent Squamous Cell Carcinoma of the Head and Neck. 2001.

19. Fatimi A, Chabrot P, Berrahmoune S, Coutu JM, Soulez G, Lerouge S. A new injectable radiopaque chitosan-based sclerosing embolizing hydrogel for endovascular therapies. Acta Biomater. 2012;8(7):2712-21. https://doi.org/10.1016/j.actbio.2012. 04.006 .

20. Kraitzer A, Ofek L, Schreiber R, Zilberman M. Long-term in vitro study of paclitaxel-eluting bioresorbable core/shell fiber structures. J Controll Release. 2008;126(2):139-48. https://doi. org/10.1016/j.jconrel.2007.11.011.

21. Rungseevijitprapa W, Bodmeier R. Injectability of biodegradable in situ forming microparticle systems (ISM). Eur J Pharm Sci. 2009;36(4-5):524-31. https://doi.org/10.1016/j.ejps.2008.12.003.

22. Li J, Mooney DJ. Designing hydrogels for controlled drug delivery. Nat Rev Mater. 2016;1:16071. https://doi.org/10.1038/ natrevmats.2016.71.

23. Cho JK, Hong JM, Han T, Yang HK, Song SC. Injectable and biodegradable poly(organophosphazene) hydrogel as a delivery system of docetaxel for cancer treatment. J Drug Target. 2013;21(6):564-73. https://doi.org/10.3109/1061186X.2013. 776055.

24. Kim DY, Kwon DY, Kwon JS, Park JH, Park SH, Oh HJ, et al. Synergistic anti-tumor activity through combinational intratumoral injection of an in situ injectable drug depot. Biomaterials. 2016;85:232-45. https://doi.org/10.1016/j.biomaterials.2016.02. 001.

25. Mao Y, Li X, Chen G, Wang S. Thermosensitive hydrogel system with paclitaxel liposomes used in localized drug delivery system for in situ treatment of tumor: better antitumor efficacy and lower toxicity. J Pharm Sci. 2016;105(1):194-204. https://doi.org/10. 1002/jps.24693. 